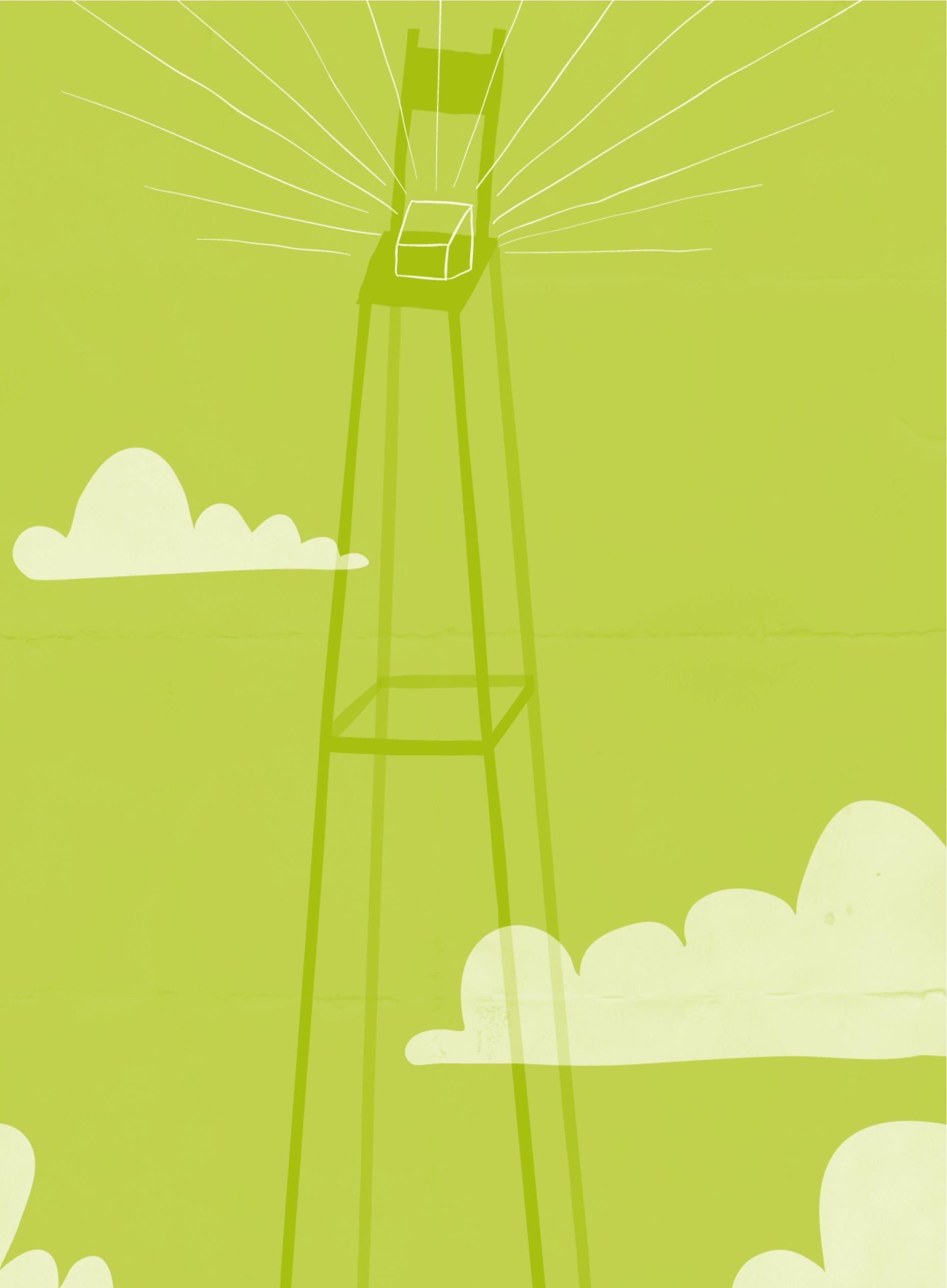




\section{Como a marca corporativa contribui para a geração de valor nas empresas}

Paula Helena de Oliveira Pereira

- Especialista em Gestão Estratégica em Comunicação Organizacional e Relações Públicas (Gestcorp) pela Escola de Comunicações e Artes da Universidade de São Paulo (ECA-USP)

- Consultora Sênior - Interbrand Londres

-paula.helena@gmail.com 


\section{Resumo}

Este artigo tem como principais objetivos discutir o papel da marca corporativa na geração de valor para as empresas e a importância em monitorar seu desempenho, além de apresentar algumas metodologias para atingir esse propósito. Grande parcela de seu conteúdo é baseada na monografia Marca: um ativo estratégico mensurável estudo exploratório, produzida como parte integrante do curso de Especialização em Gestão Estratégica em Comunicação Organizacional e Relações Públicas da Escola de Comunicações e Artes da Universidade de São Paulo (ECA-USP).

PALAVRAS-CHAVE: MARCA • PÚBLICOS ESTRATÉGICOS • AVALIAÇÃO DE MARCA • GERAÇÃO DE VALOR

\section{Abstract}

The main objectives of this article are to discuss the role of the corporate brand in creating value for companies and the importance in monitoring its performance, as well as presenting some methodologies to achieve this end. Most of the content is based on the dissertation Brand: a strategic measurable asset - exploratory study, produced for the course Specialisation in Strategic Management of Organizational Communication and Public Relations at the School of Communications and Arts of the University of São Paulo.

KEYWORDS: BRAND • STAKEHOLDERS • BRAND VALUATION • VALUE CREATION

\section{Resumen}

Este artículo tiene como principales objetivos discutir el papel de la marca corporativa en la generación de valor para las empresas y la importancia de seguir su desempeño, además de presentar algunas metodologías para alcanzar este propósito. Gran parte de su contenido se basa en la monografia Marca: um ativo estratégico mensurável - estudo exploratório (Marca: un activo estratégico mensurable. Estudio exploratorio), producida como parte integrante del curso de especialización en Gestão Estratégica em Comunicação Organizacional e Relações Públicas (Gestión Estratégica en Comunicación Organizacional y Relaciones Públicas) de la Escola de Comunicações e Artes de la Universidade de São Paulo (ECA-USP).

PALABRAS CLAVE: MARCA • PÚBLICOS ESTRATÉGICOS • EVALUACIÓN DE MARCA • GENERACIÓN DE VALOR 


\section{Importância de ativos intangíveis no valor das empresas}

N

os últimos anos, a participação dos ativos intangíveis nos balanços das empresas vem crescendo consistentemente. Segundo o Citibank, entre 1988 e 1998, a participação desses ativos subiu de $44 \%$ para $71 \%$ no balanço de um conjunto de empresas inglesas medidas pela instituição (TROIANO, 2003). Entre esses ativos estão marcas, patentes, relacionamento com os públicos estratégicos, capital intelectual e tecnologias, sendo que as marcas são consideradas por muitos estudiosos como o principal deles.

Em um mercado no qual informação e tecnologia não são mais diferenciais devido ao fácil acesso a essas ferramentas, e onde a concorrência é cada vez mais agressiva, a marca se consolida como uma vantagem cada vez mais importante. Segundo estudo publicado pela revista Business Week em parceria com a consultoria Interbrand, marcas como Coca-Cola e McDonald's representam cerca de 50\% do valor de mercado de suas companhias. Mesmo em grupos mais voltados para o público corporativo, o valor da marca chega a superar $20 \%$ do valor total de mercado da empresa, como é o caso da Intel ${ }^{1}$.

São diversos os estudos focados no processo de construção das marcas, nas ferramentas mais eficazes nesse processo e em qual a contribuição efetiva da marca para os resultados de marketing do produto ou serviço ao qual ela se refere. Porém, a contribuição da marca corporativa nesse processo e a avaliação de sua performance ainda são questões relativamente recentes.

Este artigo tem como objetivo discutir quais os elementos mais importantes na geração de valor para as empresas por meio de sua marca corporativa. Para tanto, é necessário definir o que é uma marca corporativa, qual o seu papel na performance das empresas e como monitorar seu desempenho.

\section{0 que é uma marca}

Segundo o Comitê de Definições da American Marketing Association, "marca é um no-

1 Business Week, 06 de Agosto de 2007. 
me, termo, sinal, simbolo ou desenho, ou uma combinação dos mesmos, que pretende identificar os bens e serviços de um vendedor ou grupo de vendedores e diferenciá-los daqueles dos concorrentes".

Em um mercado cada vez mais commoditizado, a marca é importante por ser elemento diferenciador para o fabricante, criando uma relação de confiança com seus diversos públicos. Entre outros benefícios proporcionados por uma marca forte estão a possibilidade da prática de preço premium, gerando maior lucratividade para as empresas e protegendo-as contra uma possível guerra de preços com a concorrência; poder de negociação com sua rede de distribuição e proteção contra eventuais crises, garantindo mais estabilidade para o negócio (KAPFERER, 1998).

Para estabelecer essa relação de confiança, é importante ter um posicionamento de marca. O posicionamento é uma idéia, uma visão que vai permear todas as ações táticas e estratégicas da empresa. Ele é manifestado em diversos pontos de contato com o cliente, tais como campanhas de marketing; notícias; qualidade de seus produtos e serviços; experiência do consumidor no ponto de venda (produtos de consumo); relacionamento com os profissionais da empresa; preços praticados; extensões de marca, entre outros (RIES \& TROUT, 1999).

Os pontos de contato com a marca variam de acordo com o segmento de atuação e a estratégia da empresa, mas nem todos são controlados por ela. Campanhas de marketing, releases, qualidade dos produtos e serviços e preços praticados estão sob controle interno, mas são diversos os elementos não controlados. Com a maior penetração da Internet, são muitos os sites que discutem boas e más experiências com produtos e serviços; com isso, a imagem de uma marca pode ser fortemente influenciada.

As diversas experiências com a marca criam percepções na mente de seus públicos; essas percepções influenciam os critérios de compra. Essa lógica também é verdade para os demais públicos da empresa, como funcionários, fornecedores, profissionais da mídia e investidores. As percepções derivadas das experiências com a marca influenciam a decisão de aceitar uma proposta de trabalho (ou de se manter na empresa), de desenvolver uma parceria comercial de longo prazo, de definir o tom de uma notícia ou de comprar uma ação da empresa.

É importante ter um posicionamento claro, coerente com os valores e ações da empresa, e manifestado de maneira consistente. Ele proporciona um vínculo entre a 
marca e seus públicos estratégicos, fazendo com que eles se sintam parte da empresa. E é esse relacionamento que pode atenuar os impactos de uma eventual crise, seja nas vendas de seus produtos e serviços, seja no valor de mercado de suas ações (SROUR, 2000).

\section{0 papel da marca corporativa na performance das empresas}

A arquitetura de marca organiza o relacionamento entre a marca corporativa e os diferentes negócios, linhas e marcas de produto da empresa. Dessa forma, o papel da marca corporativa pode ser diferente dependendo da arquitetura adotada (CLIFTON \& SIMMONS, 2004).

Em companhias com uma arquitetura de marca monolítica, a marca corporativa aparece diretamente ligada aos produtos e serviços da empresa. Com isso, as experiências derivadas dos pontos de contato com a empresa e seus produtos induzem a uma imagem única na mente do consumidor. É o caso, por exemplo, do banco brasileiro Itaú e da fabricante sul-coreana de produtos eletrônicos Samsung. Os valores da marca Itaú são manifestos de maneira única, independente do produto ou serviço. A Samsung comunica sua tecnologia avançada e design diferenciado como formas de melhorar a qualidade e estilo de vida de seus consumidores, independentemente do produto. Esse modelo de arquitetura tem como vantagem a eficiência dos programas de marketing, por proporcionar mais visibilidade à marca. Porém, caso haja algum problema com a empresa a nível corporativo, isso será refletido em seus produtos e vice-versa.

No caso de empresas com arquitetura de marca independente, modelo oposto ao monolítico, as marcas do produto criam um relacionamento direto com o consumidor. Marcas como Gillette, da Procter \& Gamble, ou Guaraná Antarctica, da Ambev, são mais fortes na mente do consumidor do que a marca corporativa e, na maioria das vezes, têm poucos atributos em comum com a marca "mãe". Nesse modelo, são necessários maiores investimentos para construir um portfólio de marcas fortes. Por outro lado, cada marca é um ativo independente que pode ser vendido separadamente caso o produto ou serviço em questão não esteja mais de acordo com a estratégia da empresa, ou não esteja produzindo os resultados desejados, sem causar nenhum dano à marca corporativa.

Há, ainda, os modelos intermediários de arquitetura de marca, nos quais a marca corporativa é mais, ou menos presente. Na arquitetura endossada, como diz o nome, a marca corporativa endossa as marcas de produto, como os chocolates Nestlé (Milkybar, Prestígio, entre outros). O modelo overbrand agrupa uma família de produtos sob uma mesma marca, como o Microsoft Office, que agrupa softwares como Microsoft Word e Microsoft Excel. Por fim, a arquitetura mista usa um ou mais modelos de arquitetura de marca (CLIFTON \& SIMMONS, 2004). 


\section{Mas qual é o papel da marca corporativa e como ela ajuda a criar valor?}

Os diferentes modelos de arquitetura de marca auxiliam as empresas a organizar a mensagem e o posicionamento de cada produto e serviço para seu público consumidor. Mas uma empresa tem diversos públicos estratégicos que contribuem para a geração de valor para a empresa e para os quais a marca corporativa é importante:

- Funcionários: uma marca corporativa forte e com uma imagem positiva no mercado tem mais facilidade na atração e retenção de talentos. Além disso, funcionários satisfeitos tendem a prestar melhores serviços aos consumidores e demais parceiros da empresa, reforçando a imagem corporativa positiva e fazendo com que o ciclo virtuoso se perpetue. O Guia das Melhores Empresas para Você Trabalhar, publicado anualmente pela revista Exame, mostra uma clara correlação entre empresas com marcas corporativas fortes e a satisfação de seus funcionários ${ }^{2}$.

- Distribuidores, fornecedores e demais parceiros: uma marca corporativa forte ajuda no poder de negociação com diversos canais de distribuição e fornecedores, e desperta o interesse em outras empresas de estabelecer parcerias comerciais de longo prazo. Além disso, um bom relacionamento com os canais de distribuição, no caso de empresas de consumo, é fundamental para que eles possam influenciar a experiência do consumidor no ponto de venda.

- Mídia: empresas com boa reputação têm também credibilidade. Agências de notícia e empresas de mídia tendem a ser favoráveis a essas companhias, seja na verificação ou na publicação de fatos relevantes.

- Investidores: a reputação de uma empresa influencia na sua classificação de risco, na atração de investimentos diretos e na compra de suas ações.

- Comunidade: a contribuição que uma empresa traz à sociedade por meio de um alto padrão de qualidade de seus produtos e serviços não é mais suficiente para gerar uma boa reputação. É necessário garantir que os pilares social, econômico e ambiental estejam em equilíbrio para que a sociedade "aceite" uma empresa em sua comunidade (KAPFERER, 1998). Esse fator é crucial para empresas mineradoras, como a brasileira Companhia Vale do Rio Doce, ou "Vale".

Para esses públicos, a noção de marca corporativa é mais clara independentemente da arquitetura de marca adotada pela empresa. É com a empresa, representada pela marca corporativa, que eles se relacionam. Além disso, uma marca corporativa forte garante a sustentabilidade do negócio no longo prazo pela representação de uma estratégia clara, baseada em valores sólidos e direcionando as ações de seus colaboradores e decisões de investimentos.

2 Disponível em: http://portalexame.abril.com.br/servicos/melhoresempresasparatrabalhar/

3 Nota: os valores da empresa nem sempre são os mesmos da marca corporativa, embora tenham uma relação próxima (CLIFTON \& SIMMONS et al., Brands and Branding, 2004). 
O grupo Votorantim é um exemplo de arquitetura de marca mista e que usa os valores da marca corporativa ${ }^{3}$ para permear as estratégias e ações de todo o grupo. O SEREU, sigla que traduz os valores da marca corporativa (solidez, ética, respeito, empreendedorismo, união) está presente desde a Votorantim Cimentos, uma das empresas do grupo mais associadas à marca corporativa, até a Citrovita, empresa dedicada à comercialização de suco de laranja concentrado. Esses mesmos valores são os que norteiam as atividades voltadas às comunidades em torno de suas fábricas ou os investimentos realizados pela venture capital do grupo.

Em suma, a marca corporativa representa internamente a razão de ser da empresa e externamente o conjunto de percepções que os diversos públicos da empresa têm em relação a ela. Essas percepções influenciam a maneira como os públicos desejam se relacionar com a empresa, contribuindo, assim, de maneiras distintas, para sua geração de valor.

\section{Como monitorar o desempenho da marca corporativa}

Em meio a pressões para resultados de curto prazo e alto retorno sobre investimentos em geral, saber a contribuição de um ativo (no caso, a marca corporativa) e a eficiência de investimentos nesse ativo é muito importante para a tomada de decisões táticas e estratégicas em qualquer companhia. Por essa razão, o monitoramento da marca corporativa não é mais de interesse apenas das áreas de comunicação corporativa ou marketing: trata-se de uma informação estratégica e, como tal, requer o comprometimento e a atenção dos altos executivos.

A maioria das empresas conduz pesquisas com foco no consumidor. No entanto, para monitorar a performance da marca corporativa, é necessária uma abordagem mais holística, incluindo os demais públicos estratégicos. Entender e agir na satisfação dos funcionários pode impactar diretamente na satisfação do cliente com os serviços da empresa, assim como um melhor relacionamento com os canais de distribuição pode impactar na rentabilidade dos produtos.

Porém, é interessante para os profissionais de Comunicação e Relações Públicas, geralmente responsáveis pelo gerenciamento da marca corporativa, conhecer quais as metodologias de pesquisa de marketing mais utilizadas para que possam ser adaptadas ou servir de inspiração para abordagens mais holísticas envolvendo todos os públicos da organização.

Escolher métricas corretas para avaliar o desempenho da marca corporativa é fundamental para que os resultados sejam relevantes como suportes para a tomada de decisão. Por exemplo, no caso de marcas de consumo, "lembrança de marca" é uma métrica bastante utilizada, mas o fato de uma pessoa lembrar de uma marca não quer 
dizer que seja propensa a ela na hora da compra; esse fator sugere que a lembrança de marca seja utilizada em conjunto com outras métricas como "preferência” ou "opinião positiva”.

Independentemente da metodologia de pesquisa utilizada, é importante que haja periodicidade nas avaliações para que se possa acompanhar a evolução da marca em relação aos atributos medidos junto ao público definido. Além disso, a qualidade da interpretação dos dados coletados é fundamental para que um plano de ação correto seja desenvolvido (AAKER, 1998).

Tradicionalmente, as pesquisas de marketing avaliam métricas voltadas ao comportamento de compra do consumidor, percepções em relação à marca (atributos de imagem) e análise competitiva, principalmente a seqüência que representa o grau de envolvimento do consumidor com a marca: conhecimento, familiaridade, preferência, lealdade e apego/recomendação (seqüência conhecida em inglês como purchase funnel). Há também modelos mais sofisticados desenvolvidos por agências de publicidade, tais como o Brand Asset Valuation, desenvolvido pela Young \& Rubicam; Brand Capital, pela DDB; ou Brand Essence, pela Leo Burnett; ou por consultorias especializadas em gerenciamento de marca, como a brasileira Troiano Consultoria.

Segundo Jaime Troiano (2003), "o valor tangivel que as marcas acabam adquirindo para as empresas decorre, essencialmente, da natureza e da intensidade da força da relação entre elas e os consumidores". Assim, se os diferentes perfis de consumidores forem classificados de acordo com a intensidade do relacionamento que têm com as marcas, será possível entender o poder da marca como um todo.

Não há dúvida de que essas pesquisas produzem resultados bastante relevantes para as empresas. No entanto, elas não estabelecem uma relação direta entre desempenho de marca e geração de valor econômico para as empresas. Para esse fim, a partir da década de 80 foram desenvolvidas diferentes metodologias de avaliação econômicofinanceira de marca.

No Brasil, as avaliações financeiras das marcas ainda são relativamente pouco comuns. No passado, a avaliação de marca era uma preocupação das áreas de contabilidade ou de administração financeira das empresas, principalmente em situações de fusões e aquisições, para que fosse determinado um preço justo do ativo a ser comprado ou vendido. Com o tempo, foi percebido que essas avaliações também são úteis na gestão do negócio (PERRIER, 2001):

- avaliação do retorno sobre os investimentos de comunicação e marketing.

- tomadas de decisões gerenciais, como alocação de recursos.

- cálculo da taxa de licenciamento da marca.

- determinação da importância da marca na composição do valor total da empresa. 
A primeira metodologia de avaliação financeira de marca foi desenvolvida pela consultoria inglesa Interbrand em 1988. Hoje, no Brasil e no mundo, há diversas consultorias que trabalham com esse tipo de avaliação. De acordo com as informações disponibilizadas por essas empresas, as metodologias diferem entre si, mas é possível observar um padrão:

1 Determina-se uma segmentação dos diversos produtos e serviços da empresa.

2 Analisam-se os resultados financeiros (histórico e futuro) de cada segmento, e deduz-se o capital empregado na operação.

3 Calcula-se a importância da marca em gerar esses resultados. As formas mais comuns de se identificar esse efeito são: determinar o quanto a marca influencia no processo de decisão de compra do consumidor (papel de marca) ou identificar a taxa de royalty que poderia ser cobrada pela utilização da marca por um terceiro. Em ambos os casos, a importância da marca é convertida em um percentual que é, então, aplicado aos dados financeiros, isolando assim os resultados futuros que se devem exclusivamente à marca.

4 Ajusta-se a taxa de desconto da empresa de acordo com a força da marca. A taxa de desconto representa a sustentabilidade dos ganhos da empresa no futuro, isto é, o risco de os ganhos projetados não se concretizarem. Quanto maior o risco, maior a taxa de desconto. Ela é utilizada para trazer os resultados projetados a valor presente, calculando-se, assim, o valor da marca. A força da marca utilizada no ajuste da taxa de desconto é geralmente determinada por uma análise competitiva com os principais concorrentes da empresa.

Pela avaliação da marca, seja ela de produto ou corporativa, é possível acessar não só o valor da marca, mas também as variáveis que contribuem para a geração desse valor e como atuar sobre elas para maximizar ganhos presentes e futuros. Entre as cinco marcas mais valiosas do mundo, três são marcas corporativas: Microsoft, IBM e GE. Vale lembrar que a marca corporativa influencia não apenas o processo de compra do consumidor, mas também todos os ganhos derivados de sua força: economia na atração e retenção de talentos; poder de negociação com fornecedores, parceiros e canais de distribuição; menores taxas de desconto e menores taxas de crédito; mais investimentos, entre outros. Essa dinâmica também é analisada durante o processo de avaliação de marca.

Na maioria dos países, não é possível reconhecer o valor de ativos intangíveis nas demonstrações financeiras das empresas devido às normas da contabilidade e à legislação. No Brasil, não existe um modelo contábil definitivo e aceito por todo o mercado financeiro nacional a ponto de ser incluído nos balanços das empresas - o que se deve, principalmente, ao caráter intangível da marca. No entanto, esse modelo seria importante devido à crescente participação dos ativos intangíveis no valor das empresas. 


\section{Conclusão}

A marca corporativa simboliza uma missão, uma visão de futuro, a razão de existir da empresa. É ela que garante a consistência das ações por um objetivo único, independentemente da arquitetura de marca da empresa.

São diversas as formas de monitorar a performance de uma marca, seja ela de produto ou corporativa. As pesquisas de marketing são diversas; a melhor alternativa depende dos objetivos de longo prazo da empresa e, portanto, do que se pretende monitorar para garantir esses resultados. Definida a ferramenta de avaliação, é importante ter um acompanhamento periódico como forma de medir o sucesso da estratégia da marca.

As avaliações financeiras das marcas ainda são pouco utilizadas no Brasil. Elas são baseadas na projeção de ganhos futuros de todos os produtos e serviços da marca em estudo, e na sua performance junto aos públicos relevantes. Seu principal benefício é promover a integração entre a performance da marca com os resultados financeiros gerados por ela.

Assim como é importante entender as percepções e atitudes do consumidor em relação às marcas de produto, é fundamental monitorar a reputação da empresa do ponto de vista dos seus diversos públicos estratégicos: funcionários, parceiros, investidores, mídia e sociedade. Dessa forma, é possível tomar decisões que irão garantir não apenas a geração de valor no curto prazo, mas também a sustentabilidade do negócio no futuro.

\section{Referências}

AAKER, D. A. Marcas - brand equity, gerenciando o valor da marca. São Paulo: Negócio Editora, 1998.

BARRETO, A. C. P. M. Avaliação econômico-financeira de marcas. Dissertação de Mestrado. São Paulo: Faculdade de Economia e Administração / Universidade de São Paulo, 1999.

BLECHER, N. e MARTINS, J. R. 0 império das marcas. São Paulo: Marcos Cobra, 1996.

CLIFTON, R. \& SIMMONS, J. et al. Brands and branding. : The Economist, 2003

KAPFERER, J. N. As marcas, capital da empresa. São Paulo: Bookman, 1998.

KAPLAN, R. S. e NORTON, D. P. Organização orientada para a estratégia. Rio de Janeiro: Campus, 2000.

KOTLER, P. Administração de marketing. 5a ed. São Paulo: Atlas, 1998.

LOPES, M. I. V. Pesquisa em comunicação. São Paulo: Edições Loyola, 2001.

MARTINS, J. R. Branding. São Paulo: Negócio Editora, 2000. 
NAVACINSK, S. D. G. 0 evento na convergência de relações públicas, publicidade e marketing - um instrumento para construção e consolidação das marcas. Dissertação de mestrado. São Bernardo do Campo: Universidade Metodista de São Paulo, 2003.

PERRIER, R. Avaliação de marca. São Paulo: Interbrand, 2001. (Capítulos selecionados)

PINHO, J.B. 0 poder das marcas. $2^{\text {a }}$ ed. São Paulo: Summus, 1996.

RIES, A.; TROUT, J. Posicionamento - a batalha pela sua mente. $8^{a}$ ed. São Paulo: Editora Pioneira, 1999.

SCHULER, M. Management of the organizational image - a method for organizational image configuration. Corporate Reputation Review, London, V.7, n. 1, p. 37-53. 2004.

SROUR, R. H. Ética empresarial. Rio de Janeiro: Campus, 2000.

TROIANO, J. A nova cultura do desejo. Jornal Meio \& Mensagem. São Paulo: M\&M Editora, 24 mar. 2003, p. 23.

Além da retórica: medindo a força da marca. Revista da ESPM. São Paulo: Editora Referência, Volume 10, Ano 9, Edição 2, Março/Abril 2003, p. 6-18.

Na Internet

http://www.brandfinance.com

http://www.businessweek.com/magazine/toc/07_32/B40450732bestbrands.htm

http://www.interbrand.com

http://portalexame.abril.com.br/servicos/melhoresempresasparatrabalhar/ 